Referencia para citar este artículo: González-Rodríguez, M. C., \& Londoño-Vásquez, D. A. (2019). Estrategias pedagógicas de literacidad: experiencia significativa en una Institución Educativa de Boyacá. Revista Latinoamericana de Ciencias Sociales, Niñez y Juventud, 17(1), 253-268. doi:https://dx.doi.org/10.11600/1692715x.17115

\title{
Estrategias pedagógicas de literacidad: experiencia significativa en una Institución Educativa de Boyacá
}

\author{
María Constanza GonZÁLEZ-RodRÍGUEZ ** \\ Profesora Institución Educativa Técnica La Libertad de Samacá, Colombia. \\ DaVId Alberto LoNdoño-VÁSQUEZ ${ }^{* * *}$ \\ Profesor Institución Universitaria de Envigado, Colombia.
}

\section{Artículo recibido en mayo 5 de 2018; artículo aceptado en agosto 17 de 2018 (Eds.)}

- Resumen (analítico): este artículo presenta los resultados obtenidos en una investigación acción educativa de tipo cualitativo, realizada en una Institución Educativa Técnica rural en un municipio de Boyacá (Colombia), donde se realizó una intervención a partir de estrategias pedagógicas para fortalecer los niveles de literacidad, teniendo en cuenta el aprendizaje significativo en su diseño dado al bajo nivel de dichos estudiantes. El soporte teórico de la investigación fue la literacidad como desarrollo de competencias en comprensión y producción escritural en contexto. La unidad de análisis fue observación directa a 6 participantes, sus respectivas pruebas de entrada y salida y 5 talleres pedagógicos. Con los resultados logrados en la investigación se evidencian avances en la mayoría de las variables evaluadas; sin embargo, al valorar los resultados finales, algunos alumnos aún presentan dificultades.

Palabras clave: aprendizaje significativo, estrategias pedagógicas, escuela primaria, literacidad, ruralidad (Tesauro de Ciencias Sociales de la Unesco).

\section{Literacy pedagogical strategies: A meaningful experience in a Boyacá's School (Colombia)}

- Abstract (analytical): This paper shows the results obtained in a qualitative, educative action research carried out in a rural Technical Educational Institution in Boyacá Department (Colombia), where an intervention was made from pedagogical strategies to strengthen literacy levels, taking into account students' meaningful learning in their design due to its students' low level. The theoretical support of the research was literacy as the development of competences in comprehension and written production in context. The analysis unit was a direct observation to 6 participants, their entry and exit tests and 5 pedagogical workshops. With the results obtained in the research, progress is evidenced in most of the evaluated variables; however, some students still presenting difficulties when the final results are assessed.

\footnotetext{
* Este artículo de investigación científica y tecnológica presenta los resultados de la investigación Desarrollo y Fortalecimiento de la Literacidad por medio de la Implementación de Estrategias Pedagógicas Significativas, en los estudiantes de segundo de primaria en una institución educativa rural de Samacá, Departamento de Boyacá en Colombia, iniciada en febrero de 2016 y terminada en junio de 2017 (acta 313.164), perteneciente al área de las Ciencias de la Educación, educación general.

** Magíster en Pedagogía de la Universidad Santo Tomás. Profesora de la Institución Educativa Técnica La Libertad de Samacá. Orcid: 0000-00017339-909X. Correo electrónico: constigo1@hotmail.com

*** Doctor en Ciencias Sociales, Niñez y Juventud, investigador de la línea Estudios Éticos, Estéticos y de Lenguaje del grupo de investigación en Psicología Aplicada y Sociedad de la Institución Universitaria de Envigado, Profesor de Tiempo Completo de la Institución Universitaria de Envigado. Researcher ID: F-8907-2013. Orcid: 0000-0003-1110-7930. H5: 9. Correo electrónico: dalondono@correo.iue.edu.co
} 
Key words: Meaningful learning, pedagogical strategies, primary school, literacy, rural living (Social Science Unesco Thesaurus).

\section{Estratégias pedagógicas de alfabetização: experiência significativa em uma Instituição de Ensino de Boyacá}

- Resumo (analítico): este artigo apresenta os resultados obtidos em uma pesquisa de ação educativa do tipo qualitativa realizada em uma Instituição de Ensino Técnico rural em um município de Boyáca (Colômbia), onde foi feita uma intervenção a partir de estratégias pedagógicas para fortalecer os níveis de alfabetização, levando em consideração o aprendizado significativo em sua desenho dado o baixo nível de tais alunos. O suporte teórico da pesquisa foi a alfabetização como o desenvolvimento de competências em compreensão e produção de escrituras em contexto. A unidade de análise foi observação direta para 6 participantes, seus respectivos testes de entrada e saída e 5 workshops pedagógicas. Com os resultados obtidos na pesquisa, evidencia-se progresso na maioria das variáveis avaliadas; no entanto, ao avaliar os resultados finais, alguns alunos ainda têm dificuldades.

Palavras chave: aprendizagem significativa, estratégias pedagógicas, escola primaria, alfabetização, ruralidade (Thesaurus de Ciências Sociais da Unesco).

\section{-1. Introducción. -2. Metodología. -3. Análisis de los resultados. -4. Análisis general y hallazgos. -5. Conclusiones. -Lista de referencias.}

\section{Introducción}

Este artículo presenta la experiencia pedagógica realizada en una Institución Educativa Técnica (IET) rural del municipio de Samacá (Boyacá). Esta IET ha presentado, históricamente, bajos resultados en las pruebas internas y externas, especialmente, en el área de lenguaje; de igual forma, los y las estudiantes muestran dificultad en los procesos de lectura y escritura, lo cual se enmarca en el escaso interés que tienen por estas, probablemente, ahincada por la falta de motivación extrínseca dada tanto en el aula como en sus hogares (Ayala \& Niño, 1997), permitiendo que la pregunta de investigación fuese ¿Cómo inciden las estrategias pedagógicas significativas en el desarrollo y fortalecimiento de los niveles de literacidad en los y las estudiantes de segundo de primaria de la IET La Libertad?

Para darle respuesta fue necesario la implementación de estrategias pedagógicas en los y las estudiantes de segundo año, a partir del fortalecimiento de los niveles de literacidad de los y las estudiantes, aplicando una serie de actividades lúdicas que fueran de agrado para los niños, haciendo posible la mejoría en la comprensión de lectura, la producción de texto, la interpretación del mensaje de la lectura y la formulación de sus opiniones acerca de lo que leen, pretendiendo mejorar el nivel académico y afianzar el proceso de aprendizaje, adquiriendo habilidades en lectura y escritura, evidenciándose cuando los y las estudiantes producen sus propios textos.

En cuanto al problema de lectura y escritura, este se presenta a nivel global en las instituciones educativas, tanto en Colombia (Alfonso \& Sánchez, 2009; Caballero, 2008; Castañeda \& Henao, 1990; Chaparro \& Vargas, 2004; Gómez, 2001; Londoño-Vásquez, 2008; Montenegro, 2010; Ramírez-López, 2014) como en otros países iberoamericanos (Cassany, 2006; Castro, Van der Veer, Burgos-Troncoso, Meneses-Pizarro, Pumarino-Cuevas, N., \& Tello-Viorklumds, 2013; Ferreiro \& Teberosky, 1979; Frade, 2009; Rosas, 2003; Soler, 2004), según lo dan a conocer los antecedentes encontrados con respecto a este tema.

Estas investigaciones señalan dificultades significativas en los procesos compositivos y comprensivos de los textos desde el proceso de formación inicial hasta el postgradual, evidenciando cómo la lectura y la escritura se entienden, cotidianamente, como una mera manipulación de un código lingüístico, la cual se adquiere a través de la repetición de actividades que permitan afianzar 
las habilidades motoras para su representación gráfica, presentándose como una actividad aislada de las interacciones sociales y culturales, en las que se está constantemente inmerso, sin hacer énfasis en las relaciones (meta)cognitivas que lleva consigo la estructuración de un texto o las características superestructurales que demanda el mismo, obviando la necesidad de desarrollar habilidades críticas que permitan ir más allá de lo literal.

Por otro lado, estas dificultades tienen una relación directa con el desempeño académico (Henao \& Londoño-Vásquez, 2017; Isáziga-David, Gabalán-Coello, \& Vásquez-Rizo, 2014); por tanto, los bajos niveles de lectura y escritura se han convertido en un problema de interés actual en el mundo académico (Carreño, Flores, \& Peñuelo, 1998; Cassany, Luna, \& Sanz, 2003; Parodi, 2010). Los autores estudiados proponen estrategias para contribuir a mejorar en cuanto a lectura y escritura desde una perspectiva sociocultural para así superar las deficiencias, facilitando el desarrollo de habilidades lectoras y escritoras, para que los y las estudiantes aprendan significativamente desde sus contextos sociales y culturales (Cassany, 2006; Friedman, 2016; Green, 2001; Kress, 2003; Philliber, Spillman, \& King, 1996; Ríos-Flórez \& Cardona-Agudelo, 2016).

Las categorías teóricas de base para esta investigación fueron literacidad, aprendizaje significativo y estrategias pedagógicas. En cuanto a la primera, la literacidad está relacionada con los procesos de comprensión y producción textual como prácticas socioculturales y lingüísticas (Cassany, 2006; Cassany et al., 2003; Castañeda \& Henao, 1990; Halliday, 1982; Londoño-Vásquez, 2015), mediadas en algunos casos por el conocimiento disciplinar (Parodi, 2010; Sánchez-Castaño, Castaño-Mejía \& Tamayo-Alzate, 2015). En relación a la construcción de niveles de literacidad en niños, los intereses investigativos se han centrado en la influencia de la familia (Aceves-Azuara \& Mejía-Arauz, 2015), las metas de desarrollo cognitivo (Torres-Velásquez, 2016) y los elementos socioculturales (Riquelme \& Quintero, 2017). Acerca del aprendizaje significativo, se rescata la necesidad de tomar los conocimientos y experiencias que los y las estudiantes ya tienen (saberes previos), para conectarlos con los nuevos conocimientos (Ausubel, 2002; Ausubel, Novak \& Hanesian, 1983), así, ellos le encuentran sentido y significado a lo que se les enseñan (Carretero, 1997; Díaz-Barriga \& Hernández-Rojas, 1999). Finalmente, en relación a las estrategias pedagógicas, estas permiten que los y las estudiantes interpreten y produzcan tanto de forma individual como grupal, relacionándose con sus compañeros y con el docente al realizar sus propias creaciones (Anijovich, Cappelletti, Mora, \& Sabelli, 2009; Díaz-Barriga \& Hernández-Rojas, 2010; Fernández, 2003; Fountas \& Pinnel, 2001).

\section{Metodología}

Es una investigación acción educativa (Carr, Benedito, Bravo, \& Kemmis, 1988; Elliott, 1991; Restrepo-Gómez, 2004), cualitativa (Esteban, 2003; Jurgenson \& Luis, 2003; Hernández-Sampieri, 2006), donde se promovió la investigación en el aula por medio de la reflexión crítica y el autocuestionamiento (Hopkins, Joyce \& Calhoun, 2002; King \& Kitchener, 1994), lo que permitió, de igual forma, indagar sobre el quehacer docente para planificar y mejorar adecuadamente la práctica educativa, es decir, centrar la atención en el mejoramiento de las prácticas (Larrivee, 2000; Richardson, 1990), donde el docente reflexiona y al mismo tiempo investiga (Ovando, 2001). ${ }^{1}$ Esta investigación procuró mejorar las prácticas educativas por medio de estrategias pedagógicas significativas, que contribuyen positivamente en desarrollo y fortalecimiento de la literacidad en los y las estudiantes de segundo de básica primaria en una institución educativa rural.

\subsection{Población y unidad de análisis}

La población son 20 estudiantes matriculados en el segundo grado en el año 2016, compuesto por 12 niñas y 8 niños con edades que oscilan entre 7 y 8 años, que habitan en una vereda del municipio

$1 \quad$ Al respecto, Elliott (1991) refiere que los docentes que quieren mejorar su práctica, «deben reflexionar siempre sobre ellos, esa reflexión dirigida a poner en práctica los valores, se puede describir como filosofía práctica; así, estas prácticas se pueden realizar para mejorar» (p. 69). 
de Samaná (Boyacá), pertenecientes a los estratos socioeconómicos 1 y 2, provenientes de familias de escasos recursos económicos y un bajo nivel de escolaridad, donde en todos los casos, el padre y la madre trabajan en actividades agrícolas, ganaderas y alimenticias, durante largas jornadas (10 a 12 horas), aspecto que dificulta el acompañamiento a sus hijos en los procesos académicos.

Los participantes fueron 3 niñas y 3 niños, seleccionados de forma intencional a través de una prueba de entrada. Esta prueba permitió clasificar a los 20 estudiantes en tres niveles según su desempeño: bajo, medio y alto. Estos niveles se tuvieron presentes en la elección de los participantes; puesto que, se escogieron una niña y un niño por nivel de desempeño en literacidad. ${ }^{2}$ Además, otro de los criterios de selección fue la autorización de sus padres para participar en la investigación a través del respectivo consentimiento informado.

Vale la pena mencionar que la categoría de análisis (Baquero \& Terigi, 1996; Marradi, Archenti, \& Piovani, 2007) se conformó, entonces, por los resultados de las pruebas de entrada y de salida de los 6 participantes (George, Fisher, \& Verhs, 2007), el diario de campo diligenciado por la investigadora principal (Hernández-Sampieri, 2006; Quintero, 2011), quien también fungía como docente encargada del grupo de segundo grado, y los talleres pedagógicos realizados (Kettula, Lampinen, Fan, \& Jiang, 2013; Mirabent-Perozo, 1990).

\subsection{Técnicas e Instrumentos}

Las técnicas e instrumentos que se utilizaron para la recolección de datos fueron:

La observación directa: se recolectó la información, observando en clase a los y las estudiantes del grado 2-02, especialmente, a los 6 participantes en el desarrollo de los talleres pedagógicos aplicados. Estas observaciones fueron registradas en los diarios de campo, allí se describió el comportamiento y las acciones de cada estudiante, luego se analizó por medio de matrices deductivas de análisis de información (Gutiérrez \& Delgado, 1999) y tabla de triangulación (Cisterna, 2005; Denzin, 2012).

La prueba de entrada y la prueba de salida: en pro de determinar los niveles de literacidad en los y las estudiantes, se realizó una prueba de entrada. ${ }^{3}$ Esta prueba permitió conocer los niveles de los 20 estudiantes, facilitando el proceso de selección de los 6 participantes, correspondientes a los tres niveles (bajo, medio y alto). Por otro lado, la prueba de salida dio elementos de comparación entre el nivel de literacidad inicial y el final, aportando elementos para valorar la intervención realizada a través de los talleres pedagógicos. ${ }^{4}$ Vale la pena mencionar que estas pruebas se diseñaron de acuerdo a las edades de las niñas y los niños y los Estándares Básicos de Competencias y los Derechos Básicos de aprendizaje (Ebcdba) de lenguaje para el grado segundo del Ministerio de Educación Nacional (MEN) de Colombia. ${ }^{5}$

Los talleres pedagógicos: Se diseñaron 5 talleres pedagógicos teniendo en cuenta los Ebcdba de Lenguaje, propuestos por el MEN. Estos talleres fueron validados por un experto, también se aplicó una prueba piloto a los y las estudiantes de 2-01. Los talleres realizados fueron:

Taller número 1- Lectura e interpretación de imágenes; se diseñó para despertar el interés hacia la lectura, por medio de una historia presentada con imágenes, donde cada estudiante observó las imágenes y escribió lo que imaginó que sucedía en forma de cuento, teniendo en cuenta experiencias vividas. Al terminar, el escrito cada estudiante comentó una experiencia que le había ocurrido, parecida a lo visto en las imágenes.

2 En relación a los participantes, durante el análisis, a estos se les asignó un código en pro de respetar el anonimato.

3 En la prueba de entrada, el texto utilizado fue la leyenda La mula de tres patas.

4 En la prueba de salida, el texto utilizado fue el cuento Escamas de dragón y hojas de sauce.

5 En el diseño de las pruebas, se eligieron lecturas diferentes, se elaboraron los cuestionarios (Londoño-Vásquez, 2015) para las dos pruebas teniendo en cuenta los mismos criterios, con preguntas que permitieron evidenciar el nivel de literacidad en cada estudiante, evaluando la comprensión e interpretación del mensaje de lectura, opiniones propias y la producción textual. Estas pruebas fueron validadas por un experto. También se realizó una prueba piloto con los y las estudiantes del grado 2-01, quienes presentaban características similares a los participantes, de esta forma se evidenció que estas pruebas funcionaban; luego, se diseñó una rúbrica con base en la propuesta por Henao, Londoño-Vásquez, Frías y Castañeda (2011) para el análisis y la valoración de la información; la información obtenida por medio de la rúbrica se sistematizó en el programa Excel. En los resultados generales se evidenció progreso en la prueba de salida con relación a la prueba de entrada. 
Taller número 2- Interpretación de imágenes y producción de texto; aquí se seleccionó un cuento infantil, se elaboró un friso con imágenes del cuento seleccionado, para motivar a los y las estudiantes a producir textos narrativos. El friso fue pegado en el tablero, donde los y las estudiantes lo observaron detenidamente; luego, narraron por escrito lo que observaron en él, creando una pequeña historia. Posteriormente, se les entregó un cuento, ellos realizaron la lectura y lo compararon con el cuento que inventaron hicieron comentarios sobre el mensaje y, por último, inventaron el final del cuento leído.

Taller número 3-Lectura silenciosa con texto descriptivo; acá se escogió la imagen de una persona y se hizo la descripción, se diseñó un pequeño cuestionario con preguntas acerca de la descripción. Al recibir el material, los y las estudiantes observaron la foto, nombraron las cualidades físicas de la persona e hicieron comentarios acerca de lo que trataría la lectura. En seguida cada estudiante realizó la lectura en silencio, después de terminar la lectura se hizo la deducción de algunas palabras nuevas para ellos y se hicieron comentarios acerca de los sentimientos de la persona. Por último, cada estudiante hizo la descripción, utilizando sus propias palabras y desarrollaron el cuestionario dado.

Taller número 4- Lectura guiada en voz alta; en este taller se seleccionó un cuento infantil, el cual fue transcrito e impreso, dejándolo sin terminar, para que los y las estudiantes practicaran la producción de texto, narrando un final inventado por cada uno; también se diseñó un cuestionario de análisis y reflexión, teniendo en cuenta la lectura.

Taller número 5- Cuenta cuentos e interpretación del mensaje; finalmente, se escogió un cuento con diálogo y mensaje, para desarrollar la comprensión e interpretación, como también la habilidad para hablar ante sus compañeros. Cada estudiante leyó una parte del cuento en voz alta. Al terminar la lectura se hicieron comentarios y reconstrucción del cuento; posteriormente, cada estudiante narró ante sus compañeros el cuento teniendo en cuenta la secuencia, como última actividad desarrollaron el cuestionario relacionado con el cuento leído. ${ }^{6}$

\subsection{Competencias en literacidad para los y las estudiantes de segundo grado de primaria en Colombia}

Para el diseño y la revisión de las pruebas de entrada y de salida empleadas en la investigación, se realizó una lista de 10 competencias en literacidad, las cuales podrían ser las competencias que un o una estudiante de segundo grado de primaria en Colombia obtenga al culminar dicho grado. Estas fueron seleccionadas de los diferentes autores base (Cassany, 2006; Castañeda \& Henao, 1990) y de los documentos ministeriales como los Derechos Básicos de Aprendizaje y los Estándares Básicos de Competencias para el área de lenguaje y consolidadas en la siguiente tabla.

Tabla 1. Competencias de literacidad para los y las estudiantes de segundo grado de primaria en Colombia

\begin{tabular}{|c|c|c|}
\hline No. & $\begin{array}{c}\text { Competencias en literacidad para grado segundo de primaria en } \\
\text { Colombia }\end{array}$ & Autores \\
\hline 1 & Diferenciar los tipos de significados y los diferentes tipos de texto. & Cassany (2006) \\
\hline 2 & Lee y explica el mensaje principal de un texto escrito o un gráfico. & Derechos Básicos de Aprendizaje \\
\hline 3 & $\begin{array}{l}\text { Expresar en forma clara las ideas y sentimientos, según lo amerite la } \\
\text { situación comunicativa. }\end{array}$ & $\begin{array}{l}\text { Estándares Básicos de } \\
\text { Competencias }\end{array}$ \\
\hline 4 & $\begin{array}{l}\text { Lee en voz alta, con fluidez (dicción y velocidad) y con entonación } \\
\text { adecuada según el mensaje del texto. }\end{array}$ & Derechos Básicos de Aprendizaje \\
\hline 5 & $\begin{array}{l}\text { Producir textos, utilizando un vocabulario adecuado para expresar las } \\
\text { ideas. }\end{array}$ & $\begin{array}{l}\text { Estándares Básicos de } \\
\text { Competencias, Cassany (2006) }\end{array}$ \\
\hline
\end{tabular}

6 Es importante mencionar que el análisis de los talleres se realizó a través de las rúbricas propuestas por Londoño-Vásquez (2015). 


\begin{tabular}{|c|c|c|}
\hline No. & $\begin{array}{c}\text { Competencias en literacidad para grado segundo de primaria en } \\
\text { Colombia }\end{array}$ & Autores \\
\hline 6 & $\begin{array}{l}\text { Identifica los personajes principales de una historia y las acciones que } \\
\text { cada uno realiza. }\end{array}$ & Derechos Básicos de Aprendizaje \\
\hline 7 & $\begin{array}{l}\text { Lee símbolos, señales, imágenes e historietas que están en libros, } \\
\text { en la calle o en la escuela y expresa de manera escrita y oral lo que } \\
\text { comprende de estas. }\end{array}$ & Derechos Básicos de Aprendizaje \\
\hline 8 & Argumentar; expresando en forma clara las ideas. & $\begin{array}{l}\text { Estándares Básicos de } \\
\text { Competencias }\end{array}$ \\
\hline 9 & $\begin{array}{l}\text { Escribe resúmenes de textos informativos leídos o escuchados } \\
\text { utilizando sus propias palabras. }\end{array}$ & $\begin{array}{l}\text { Derechos Básicos de Aprendizaje, } \\
\text { Castañeda y Henao (1990) }\end{array}$ \\
\hline 10 & $\begin{array}{l}\text { Reconoce la estructura de un texto y lo cuenta con sus propias } \\
\text { palabras siguiendo la secuencia de la historia (Introducción, nudo y } \\
\text { desenlace). }\end{array}$ & Derechos Básicos de Aprendizaje \\
\hline
\end{tabular}

\subsection{Procedimiento de recolección de la categoría de análisis}

Al inicio del 2016, los 20 estudiantes participantes presentaron la prueba de entrada. Los resultados permitieron conocer los niveles de literacidad a partir de las 10 competencias seleccionadas (Ver 2.3). De allí, se seleccionaron, de forma intencionada, 3 niñas y 3 niños, que pudieran estar clasificados en nivel bajo, medio y alto.

Posteriormente, se realizaron cinco talleres pedagógicos orientados a mejorar los niveles de literacidad en los y las estudiantes y diseñados con base en las competencias de la Tabla No.1. Estos fueron realizados con una periodicidad quincenal, afianzando la comprensión lectora y la producción de texto durante toda la semana. Después de terminar la aplicación de los talleres pedagógicos, se realizó la prueba de salida, para comparar los niveles iniciales y finales de literacidad en los y las estudiantes ${ }^{7}$.

\section{Resultados}

\subsection{Prueba de entrada}

Los 6 participantes presentaron esta prueba con el resto de los y las estudiantes bajo las mismas condiciones. Los resultados obtenidos y la autorización de sus padres a través del consentimiento informado fueron los criterios para seleccionar los 6 participantes de los 20 estudiantes. Los resultados obtenidos fueron:

- La y el estudiante M1 y H1 obtuvieron los puntajes más bajos con 6 y 7 variables con nivel de desempeño insuficiente.

- La y el estudiante M2 y H2 obtuvieron puntajes de 5 y 6 variables con nivel de desempeño aceptable.

- La y el estudiante M3 y H3 obtuvieron puntajes 5 aceptables y 5 esperados.

7 La rúbrica diseñada para la revisión tanto de las pruebas como de los talleres, contó con tres conceptos evaluativos cualitativos: Esperado, Aceptable, Insuficiente; con valores o puntuación de 2 puntos, 1 punto y 0 puntos, respectivamente. Esta fue validada a través de expertos. 
Gráfica 1. Resultados prueba de entrada de cada participante con niveles de desempeño

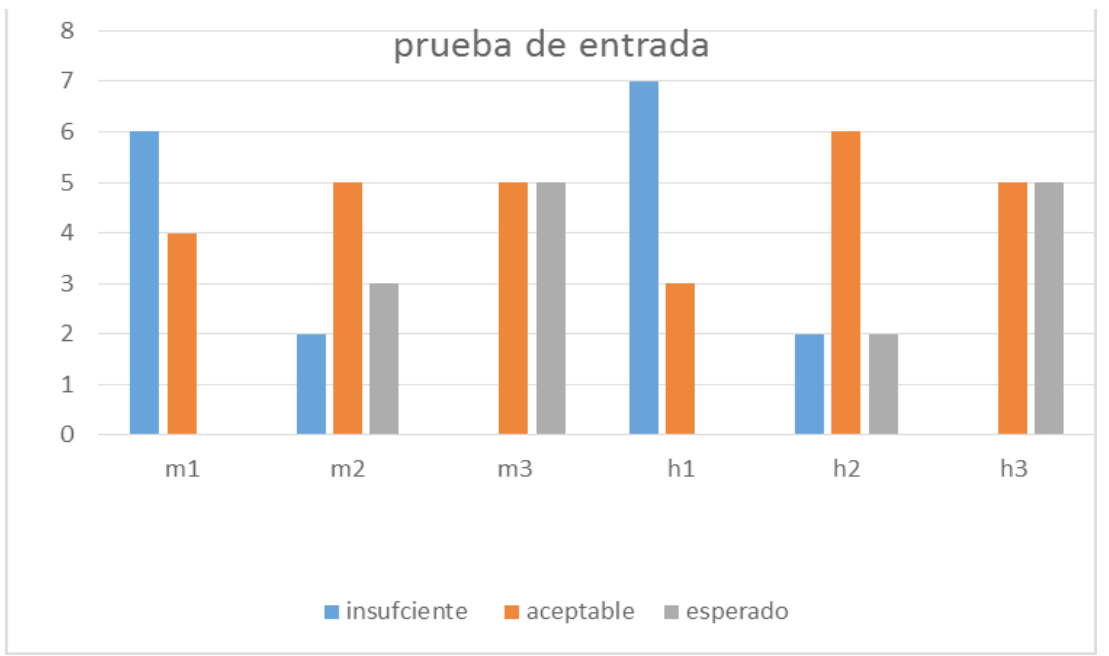

Algunas de las respuestas dadas por los participantes en esta prueba,${ }^{8}$ evidencian aspectos de comprensión lectora y producción escritural. A la pregunta, ¿Qué es un arriero? Algunas de las respuestas fueron:

«el arriero es un machete.» $\mathrm{H} 1$

«el ariero escomo areaban las mulas poreso lo llana areaba.» M1

«un arriero es el que se dedica a empujar las mulas.» $\mathrm{H} 2$

«un arriero es una persona que le echaba carga a la mula.» M2

«Un arriero es una persona que empuja a los animales para que caminen más rápido.» $\mathrm{H} 3$

«Un arriero es un señor que empuja a las mulas para que caminen mas rápido.» M3

Si se analizan los aspectos tanto sintácticos como semánticos, H1 presentó una dificultad semántica y M1 falencias sintácticas. Por otro lado, los otros 4 participantes cumplieron con la construcción conceptual solicitada.

Por otro lado, a la pregunta ¿Qué piensas de las personas que maltratan a los animales?, las respuestas fueron:

«Está tan furioso que empezó a golpear a la mula con un machete.» $\mathrm{H} 1$ "que son malos con los animales y eso es no querer la naturaleza.» M1

«que no debemos maltratar a los animales que hay que cuidarlos.» $\mathrm{H} 2$

«yo pienso que eso no se ace porque si uno maltrata a un animal se be feo y orrible.» M2

«Pienso que el que maltrata a los animales lastima a la naturaleza.» $\mathrm{H} 3$

«yo pienso de las personas que maltratan a los animales que no agan eso porque pueden ir a la carsel.» M3

Al respecto, en esta ocasión, solo H1 no interpretó el mensaje de la leyenda. Este tipo de dificultades fueron recurrentes en $\mathrm{H} 1$ y en M1 durante la prueba, aspecto que podría apoyar la propuesta de código restringido (Bernstein, 1989), la cual centra su atención en la relación familia, lenguaje y educación. En otras palabras, si bien el aprendizaje significativo se relaciona con los puentes cognitivos que se puedan crear entre el conocimiento nuevo y el conocimiento consolidado como las experiencias, la memoria y su hábitat (Ausubel et al., 1983), hay un elemento más fuerte como es el lenguaje y las interacciones realizadas entre los miembros de la familia que permiten que haya una construcción simbólica del concepto y, de igual forma, se desarrollen las competencias discusivas para enunciarlo, describirlo o explicarlo a otros (Halliday, 1982).

8 En la transcripción de las respuestas se mantienen los aspectos de puntuación, ortografía y acentuación del original. 


\subsection{Talleres pedagógicos}

Con base en los resultados, anteriormente mencionados, los investigadores diseñaron 5 talleres pedagógicos (Ver 2.2), los cuales fueron realizados durante el primer semestre de 2016. Si bien las evidencias cualitativas permiten ver el grado de las 10 competencias evaluadas inicialmente, en pro del espacio requerido para tal información, solo se hará referencia a uno de los talleres y, posteriormente, se comparan los resultados de los 5 talleres.

Teniendo en cuenta lo anterior, el primer taller fue el más significativo de los cinco realizados. Especialmente, en lo concerniente a H1, en relación a la descripción y los procesos escriturales que este requiere.

Gráfica 2. Resultados de cada participante en el taller 1, con niveles de desempeño

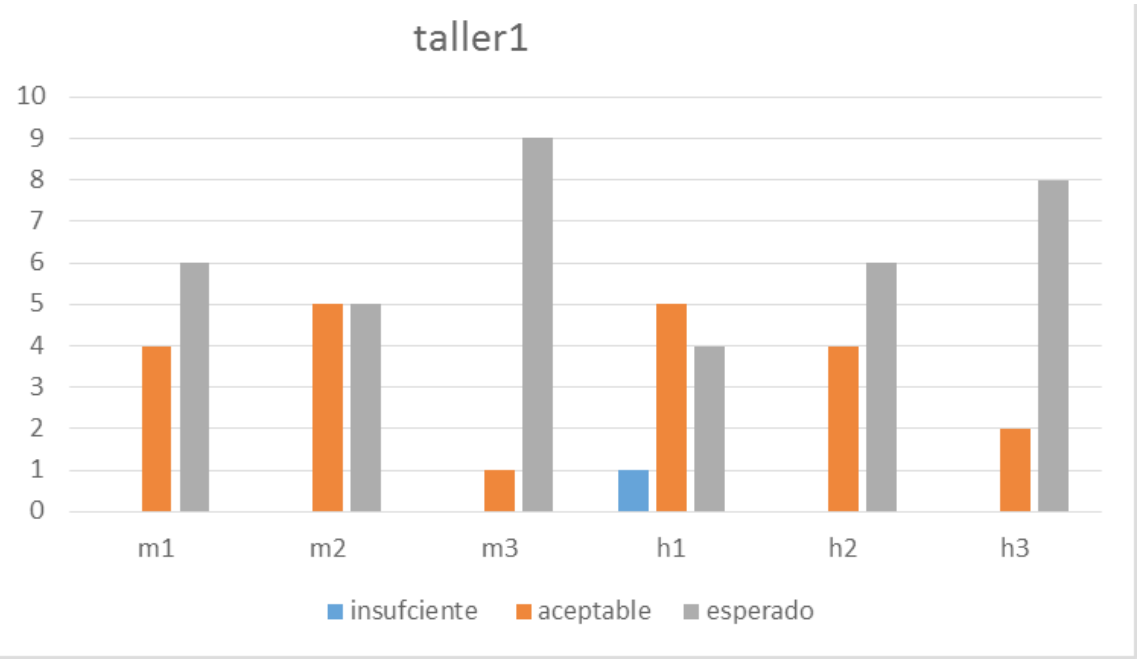

Acerca de la producción de texto, los resultados fueron los siguientes:

H1 al inventar el cuento hizo una corta descripción de lo que se ve en las imágenes:

"La mamá y el niño estaban caminando y el niño incontro un armario con juguetes, mientras el niño jugaba con los juguetes la mamá caminando y después el niño se puso triste y sesento en el suelo, y el niño se incontro con un polisia y la mamá estaba muy feliz y abria los brazos lo iba abrasalo.»

M1 presenta una mejor producción textual, al escribir el cuento acerca de las imágenes observadas lo hizo utilizando la imaginación:

«El niño estaba feliz con su mamá salieron a comprar juguetes en la tienda con su mamá y lo cogio de la mano la mamá al niño, el niño queria un carito bonito y su mamá queria comprarle un juguete bonito, el niño se perdio de su mamá y estaba muy triste pero un polisia lo encontró muy triste y se lo llebo a su mamá, cuando la mamá lo bio y se puso muy feliz y corio abrasarlo.»

$\mathrm{H} 2$, en la producción del cuento, utilizó la imaginación usando algunas palabras de su entorno: "Una señora estaba trastiando a su hijo para una juguetería y el niño cojio un carito y la señora estaba mirándolo y después el niño cojio el balón y se puso a jugar con su mamá y el niño estaba triste porque su mamá se fue y lo dejo solito y un policía lo topo solito y se lo llevo para donde su mamá.»

M2 al observar las imágenes, inventó un cuento utilizando su imaginación: "Un día la mamá se fue con su hijo a la jugeteria a comprar jugetes para el hijo la mamá bailaba y su hijo estaba triste porque la mamá lo regaño y después la mamá le dijo al niño que si queria salir a jugar al cojido y el niño no salio a jugar y la mamá le pego y al otro día se fuera para la administración municipal y se encontró con un policía que lo alludo 
para que su mamá no lo bolbiera a regañar y a pegar y el niño trabaja día a día trabaja y estudia.»)

H3 observó las imágenes y creó su cuento utilizando ampliamente su imaginación:

«Un día la mamá de un niño llamado Diego fueron a la jugueteria a comprar juguetes Diego eligio un carrito de color azul para que jugaran con su hermano que se llamaba Cristian su mamá no se lo dejo comprar el niño se puso a yorar y no le hizo caso a su mamá, el niño se perdio y un oficial lo encontro, su mamá le compro y pudo jugar con su hermano.»

En relación a M3, al observar las imágenes, ella escribió su cuento así:

"Habia una vez un niño llamado Pepito que estaba con su mamá Pepito estaba muy feliz porque iba a una jugueteria, en donde habian balones, aviones, y carros. Un día Pepito se perdio en la jugueteria y se sentía muy triste porque se había perdido. De pronto un policia encontro a Pepito y se lo yebo a mamá y Pepito se sintió muy feliz y vivieron muy felices por siempre.»

Acá es posible evidenciar en los diferentes enunciados, no solo el logro de la actividad sino también la calidad de los enunciados desde los niveles sintáctico y semántico, donde la narración y la descripción surgen como opciones concretas para construir el texto solicitado. De igual forma, se observa cómo el primer taller acompaña el diagnostico arrojado por la prueba de entrada y da una mirada más cualitativa a los niveles de literacidad de estos participantes.

Además, gracias al taller realizado, en estos enunciados no solo se encuentran aspectos relacionados con la producción escritural como las competencias 3 (Expresar en forma clara las ideas y sentimientos, según lo amerite la situación comunicativa), 5 (Producir textos, utilizando un vocabulario adecuado para expresar las ideas) y 10 (Reconoce la estructura de un texto y lo cuenta con sus propias palabras siguiendo la secuencia de la historia) de la Tabla 1, sino también de la comprensión lectora y los procesos cognitivos que giran alrededor de esta, enunciados en las competencias 1 (Diferenciar los tipos de significados y los diferentes tipos de texto), 2 (Lee y explica el mensaje principal de un texto escrito o un gráfico) y 6 (Identifica los personajes principales de una historia y las acciones que cada uno realiza) de la misma tabla, aspectos que son recurrentes en los otros 4 talleres realizados.

En relación a esta recurrencia, en la gráfica 3, se comparten los resultados obtenidos por los 6 participantes en los 5 talleres. Estos resultados fueron clasificados en tres opciones de valor: Insuficiente (I), Aceptable (A) y Esperado (E), aplicados a las 10 competencias propuestas en la Tabla 1.

Gráfica 3. Comparación de los resultados de los talleres pedagógicos realizados

\section{Comparación de los Resultados de los Talleres}

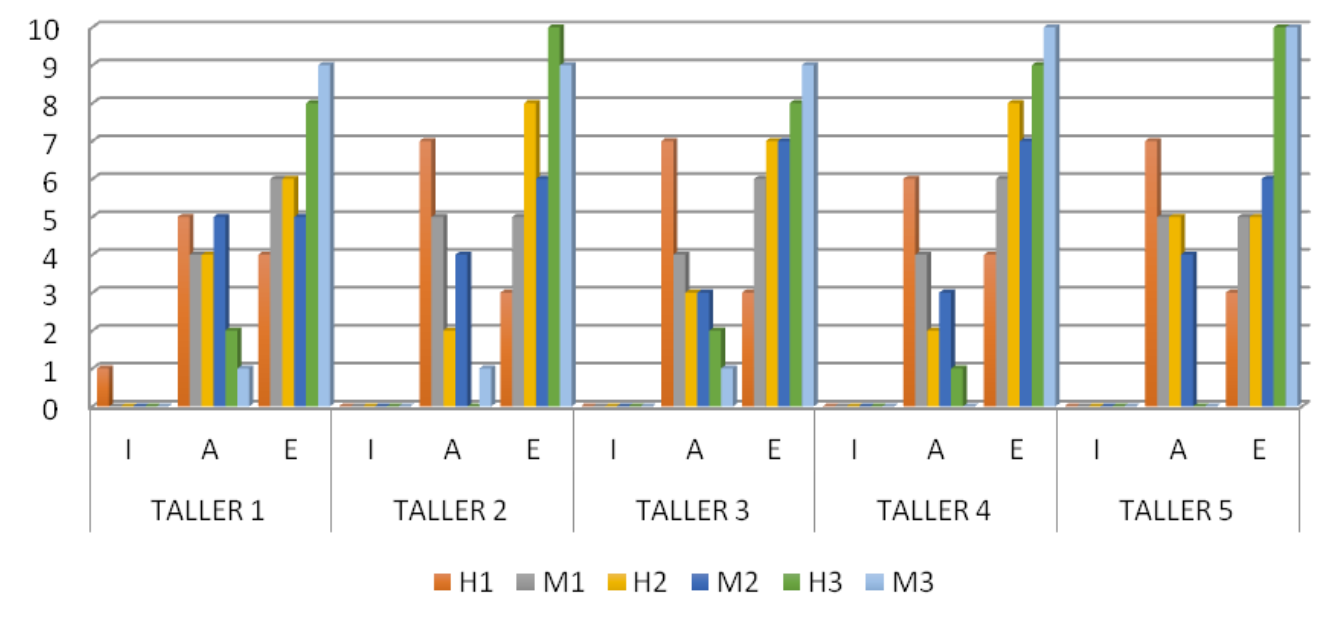

Rev.latinoam.cienc.soc.niñez juv 17 (1): 253-268, 2019 
En la anterior gráfica es posible rastrear el desempeño individual de cada uno de los participantes. Por ejemplo, para el taller 1, H1 obtuvo 1 competencia en insuficiente, 5 en aceptable y 4 en esperado. En el taller 3, el mismo participante (H1) obtuvo 7 competencias en aceptable y 3 en esperado, mejorando considerablemente su desempeño en la prueba de entrada y el taller 1. Además, estos resultados se mantuvieron en los otros dos talleres, demostrando un desarrollo de competencias de comprensión y producción textual y, por tanto, un mejoramiento de los niveles de literacidad.

Por último, es significativo el avance cualitativo de los 6 participantes en cada uno de los talleres, afianzando aspectos requeridos para su desempeño académico (Bernstein, 1989; Castañeda \& Henao, 1990; Halliday, 1982; Londoño-Vásquez, 2015) y la construcción de conocimiento significativo para su realidad y su entorno (Ausubel, 2002; Ausubel et al., 1983). De igual forma, la práctica docente de la profesora-investigadora también se ve directamente retroalimentada tanto por los resultados de sus estudiantes $\mathrm{y}$, principalmente, los participantes y las reflexiones temáticas, pedagógicas y didácticas requeridas para el diseño de los talleres y su realización (Carr, Benedito et al., 1988; Hopkins et al., 2002; King \& Kitchener, 1994; Larrivee, 2000; Ovando, 2001; Richardson, 1990).

\subsection{Prueba de salida}

La prueba de salida se realizó una semana después de terminar la aplicación de los talleres pedagógicos. El material que se utilizó para esta prueba fue el cuento Escamas de dragón y hojas de sauce del autor Terry Gívens (1998). Con respecto al objetivo de esta prueba fue evidenciar los avances en el desarrollo de la literacidad y comparar los niveles iniciales y finales de literacidad en los y las estudiantes, después de la implementación de los talleres pedagógicos. Para esta prueba se realizó la lectura del cuento y el desarrollo del cuestionario teniendo en cuenta las mismas categorías de la prueba de entrada.

Gráfica 4. Resultados de cada participante en la prueba de salida, con niveles de desempeño

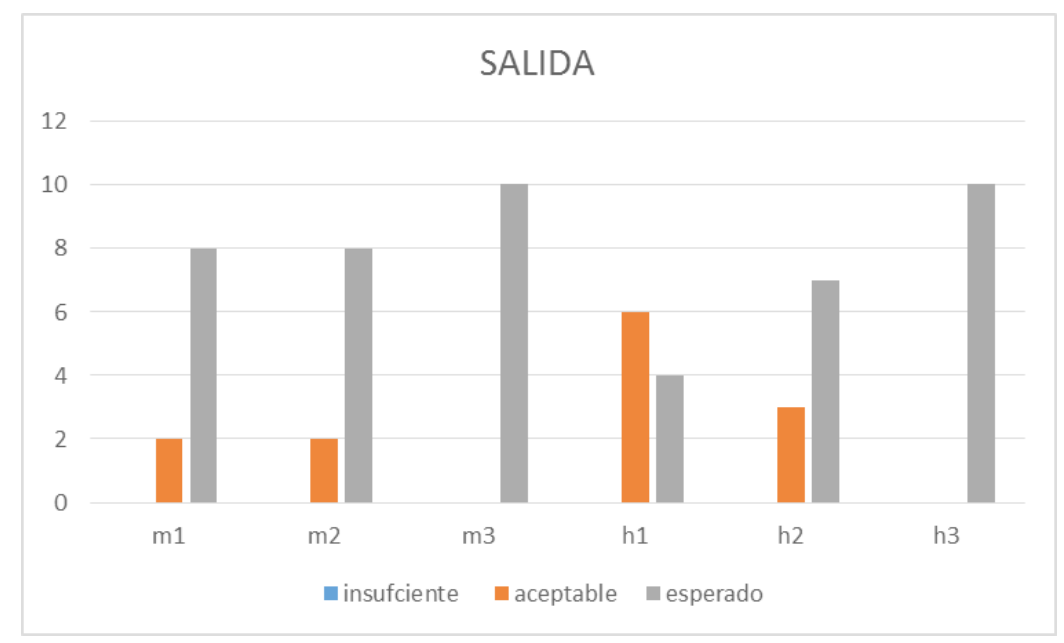

La gráfica No. 4 señala que ninguno de los participantes obtuvo una competencia en insuficiente. Además, M1 fue la participante que mayor mejoría cualitativa tuvo en las mediciones, tanto que consiguió los mismos resultados que M2 y mejores que H2. De igual forma, M3 y H3 alcanzaron unos resultados altamente deseados, con las 10 competencias en esperado. En cuanto a H1, obtuvo 6 competencias en aceptable y 4 en esperado. Estos resultados son coherentes con los analizados en la gráfica 3, especialmente, en los talleres pedagógicos 3, 4 y 5. Los resultados de los 6 participantes son altamente deseados para los procesos educativos para el grado segundo de cualquier institución educativa, especialmente, si recordamos las condiciones de ruralidad (Ayala \& Niño, 1997), socioculturales (Cassany, 2006) y de capital simbólico (Bourdieu, 2008) en los cuales están inmersos los participantes. 
Por otro lado, en comprensión de lectura se evidenciaron mejores resultados a las preguntas: ¿A dónde fueron Juan y Raquel y qué buscaban?

«Juan y Raquel fueron al bosque en busca de un tesoro y de un nido petirrojos.»

$\mathrm{H} 1$

«Juan fue en busca de un tesoro escondido y Raquel fue en busca de un nido de petirrojos.» M1

«Juan y Raquel fueron al bosque Juan estaba buscando un tesoro y Raquel unos petirrojos.» $\mathrm{H} 2$

«Juan y Raquel fueron al bosque Juan iba en busca de un tesoro y Raquel iba en busca de unos pajaros petirrojos.» $\mathrm{M} 2$

«Juan y Raquel fueron al bosque pero no buscaron lo mismo Juan iba en busca de un tesoro y Raquel en busca de un nido de petirrojos.» $\mathrm{H} 3$

"Juan y Raquel fueron al bosque, Juan fue en busca de un tesoro escondido y Raquel en busca de un nido de petirrojos.» M3

Al respecto, $\mathrm{H} 1$ muestra mejoría en comprensión de lectura al contestar la pregunta de forma acertada de acuerdo con lo leído; M1 y M2 presentan seguridad al dar su respuesta de forma adecuada acorde con la lectura; M3, H2 y H3 responden acertadamente relacionada con la lectura.

Al observar y comparar los resultados obtenidos en la prueba de entrada y la prueba de salida, se evidencian resultados positivos.

Gráfica 5. Comparación de los resultados de las pruebas de entrada y salida de los 6 participantes

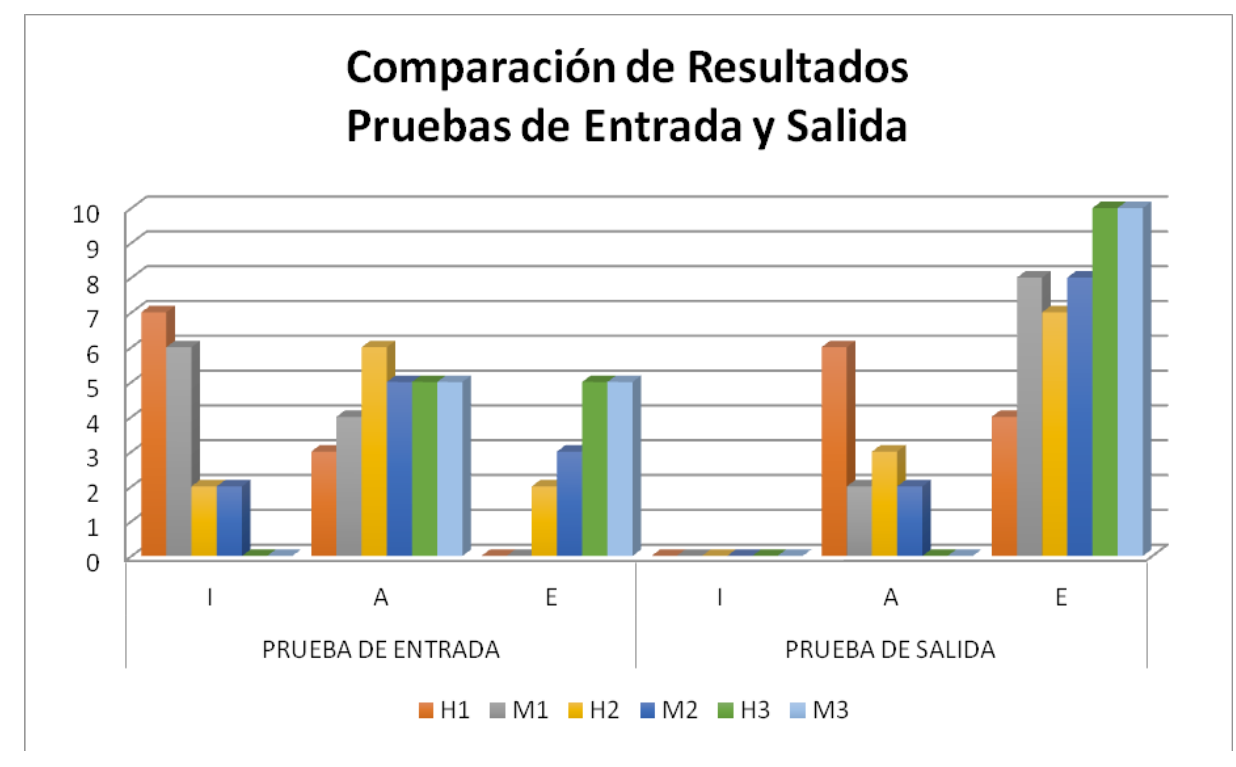

En la prueba de salida se evidencia una situación diferente con respecto a la prueba de entrada; puesto que, ya no se obtuvieron puntajes de nivel de desempeño insuficiente, los puntajes de aceptable fueron menores y los puntajes de esperado aumentaron.

Cabe anotar que en uno de los y las estudiantes seleccionados aún se evidencia dificultad en las variables de interpretación del mensaje y expresar sus opiniones, obteniendo un nivel de desempeño aceptable; y tres estudiantes mostraron avance en la variable de interpretación del mensaje, pero en la variable de dar las opiniones, su nivel es aceptable. Estos resultados y la experiencia vivida, dieron elementos profesionales y experienciales a la docente-investigadora para sus futuras prácticas 
pedagógicas, permitiéndole darse cuenta de aspectos que influyen los procesos de aprendizaje y algunas opciones pedagógicas que pueden ser significativas para afianzar dicho proceso. ${ }^{9}$

\section{Discusión y hallazgos}

Teniendo en cuenta la pregunta propuesta para esta investigación, se evidenció una incidencia significativa con la implementación de las estrategias pedagógicas en pro del desarrollo de los niveles de la literacidad para los y las estudiantes de segundo grado de la institución en mención. Pues aspectos como la motivación por la lectura y la creación de textos se afianzaron en los participantes, especialmente, al estimular el uso del vocabulario de su entorno y la posibilidad de relacionar la lectura con algunas vivencias de su vida cotidiana. Por tanto, se deduce que los y las estudiantes pueden desarrollar capacidades para producir sus propios textos, relacionando con el entorno y con su vida cotidiana, aspecto que en algunas instituciones se sataniza o encaja como aspecto no deseable. En otras palabras, cuando se relacionan los textos producidos y las variables lingüísticas con las variables socioculturales, se obtienen mejores resultados, pues los textos son producidos por seres sociales con un desarrollo lingüístico propiciado por su entorno, potenciado por la escuela (LondoñoVásquez, 2015).

Así mismo, los y las estudiantes adquieren las habilidades de lectura y escritura, como también el desarrollo de la escucha y el habla, estas habilidades deben transformarse en herramientas para favorecer la construcción de conocimientos, para comunicarse con eficacia en las situaciones de la vida cotidiana. Por eso la escuela debe desarrollar propuestas metodológicas y didácticas para potenciar dichas habilidades desde un punto de vista comunicativo.

En este caso es importante anotar que por medio de los talleres pedagógicos, los y las estudiantes alcanzaron habilidades para usar su imaginación e interpretar el mensaje que deja la lectura, haciendo comentarios acerca de lo que leen, para luego producir sus propios textos y dar a conocer sus opiniones de forma oral y escrita. Acá se observa una relación importante entre la literacidad y el desarrollo metacognitivo de los participantes, potenciando su desempeño académico (Henao \& LondoñoVásquez, 2017). Pues, «El uso de la literacidad es fundamentalmente social, por tal razón se ubica en la interacción interpersonal y en lo que la gente hace con los textos leídos o escritos» (Cassany, 2009, p. 24).

Por otra parte, con las observaciones y el desarrollo de los talleres se evidenció que el nivel de interpretación y dar opiniones no es el esperado, pero se logró mejorar la comprensión de lo que leen, para luego narrarlo ante sus compañeros, siguiendo la secuencia de lo que ocurre en el cuento y desarrollar cuestionarios acerca de lo leído. Además, hay mayor concentración en la lectura silenciosa para la comprensión, ya que contestan adecuadamente las preguntas sobre comprensión de lectura, para luego producir textos teniendo en cuenta lo leído, logrando mejorar la interpretación del mensaje de la lectura. Al respecto, Ausubel (2002) afirma que «al estudiante sólo se le exige que comprenda el material y lo incorpore a su estructura cognitiva con el fin de que esté disponible para su reproducción, para un aprendizaje relacionado o para resolver problemas en el futuro» (p. 33).

Si bien los resultados obtenidos parecen ser satisfactorios, la implementación contó con algunas dificultades. Una de ellas es el contexto sociocultural de las familias de los participantes, pues en varias ocasiones no se contó con un apoyo real por parte de los padres en cuestión del seguimiento y acompañamiento de los procesos académicos propuestos para el hogar. Aspecto entendible si se recuerda que la mayoría de ellos solo terminaron primaria y se dedican a actividades agrícolas como su opción de obtener el sustento.

En cuanto a la posibilidad de replicar la implementación al resto de los grados de la Institución,

$9 \quad$ Al respecto, Díaz y Hernández (1999) señalan que: «Las estrategias coinstruccionales apoyan los contenidos curriculares durante el proceso mismo de enseñanza o de lectura del texto de enseñanza. Cubren funciones como las siguientes: detección de la información principal; conceptualización de contenidos; delimitación de la organización, estructura e interrelaciones entre dichos contenidos, y mantenimiento de la atención y motivación» (p. 72). 
hubo dificultades de tipo administrativas y académicas. Puesto que, este tipo de proyectos académicos demandan voluntades, capacidades y recursos y, en algunas ocasiones, no todas confluyen en un mismo espacio. No obstante, un número importante de colegas, asumieron otra mirada frente a la literacidad, el diseño didáctico y las posibilidades de revisar sus prácticas pedagógicas, como fue el caso de la investigadora.

Si bien en esta ocasión, los participantes pudieron desarrollar mejores niveles de literacidad y subsanar algunas falencias en relación al tema. Es vital continuar consolidando dichos niveles en pro de alcanzar los deseados, al menos, a aquellos propuestos por el MEN para los y las estudiantes de primaria y, posteriormente, secundaria.

Finalmente, para seguir el proceso del desarrollo y fortalecimiento de la literacidad se debe continuar con la implementación de estrategias pedagógicas significativas por medio de actividades que permitan el desarrollo de habilidades y capacidades para afianzar los niveles de literacidad, lo cual posibilita un aprendizaje eficaz y, por consiguiente, el mejoramiento en el rendimiento académico de los participantes. Estas estrategias pueden tener aplicabilidad en diferentes contextos educativos de básica primaria, ajustándolas a las necesidades de las Instituciones Educativas que requieran o consideren importante desarrollar los niveles de literacidad de los y las estudiantes.

\section{Conclusiones}

Al cierre de esta investigación se puede concluir que la literacidad parte del proceso de la lectura y la escritura, teniendo en cuenta el contexto sociocultural, donde se desenvuelven los y las estudiantes.

Por medio del análisis de las pruebas y los talleres se evidenció el progreso del desarrollo de la literacidad en los y las estudiantes; según los resultados de la prueba de entrada y el proceso que se llevó con cada uno de los talleres, se logró despertar la motivación por la lectura y por la producción textual, fomentando la participación activa de los y las estudiantes, por tanto, esto confirma que desde la Institución Educativa se debe buscar de forma activa que los y las estudiantes se interesen por la lectura y la escritura para poder obtener resultados significativos.

Si se tienen en cuenta los resultados obtenidos en la prueba de salida, se logró una mejoría en cuanto a los niveles de literacidad; por tanto, la implementación de estrategias pedagógicas con actividades de lectura y escritura favorecen el desarrollo de estas 10 competencias.

A pesar que aún se presentan dificultades en algunos participantes es evidente que se obtuvo una mejoría; por consiguiente, se debe tener en cuenta que el proceso para lograr un buen nivel de literacidad, es lento especialmente en los y las estudiantes que presentan dificultades. Este proceso se va desarrollando con la práctica en el transcurrir de la vida escolar, lo cual es importante que se inicie en los primeros niveles de escolaridad, para así despertar habilidades y placer por la lectura y la escritura por medio de estrategias que los motiven. En cuanto a la capacidad para interpretar el mensaje de la lectura y dar opiniones, aún se presenta dificultad; entonces en estas variables es a las que más se debe reforzar en los talleres pedagógicos, sin descuidar los diferentes ritmos de aprendizaje y las necesidades individuales que presentan los y las estudiantes.

En cuanto a las limitaciones, se reconoce que fue una unidad de análisis restringida, lo cual no permite señalar tendencias, pero sí conocer los niveles de literacidad de los participantes tanto al inicio como al final de la intervención, a través de las estrategias didácticas propuestas.

Finalmente, en cuanto a una futura línea de investigación, se recomienda realizar un estudio de tipo experimental de tipo pre-post para comprobar estadísticamente los efectos de la intervención realizada y ampliarla a un mayor número de participantes.

\section{Lista de referencias}

Aceves-Azuara, I., \& Mejía-Arauz, R. (2015). El desarrollo de la literacidad en los niños. En R. Mejía-Arauz (coord.), Desarrollo psicocultural de niños mexicanos (pp. 75-118). Guadalajara, Jalisco: Iteso. 
Alfonso, D., \& Sánchez, C. (2009). Comprensión Textual, Primera Infancia y Educación Primaria. Bogotá, D. C.: Ecoe Ediciones.

Anijovich, R., Cappelletti, G., Mora, S., \& Sabelli, M. (2009). Transitar la formación pedagógica: dispositivos y estrategias. Barcelona: Paidós.

Ausubel, D. (2002). Aquisición y Retención del Conocimiento. Barcelona: Paidós, Saicf.

Ausubel, D., Novak, J., \& Hanesian, H. (1983). Psicología Educativa: un punto de vista cognoscitivo. México, D. F.: Trillas.

Ayala, M., \& Niño, J. E. (1997). La comprensión lectora ventana al mundo. Tunja: Universidad Santo Tomás.

Baquero, R., \& Terigi, F. (1996). En búsqueda de una unidad de análisis del aprendizaje escolar. Apuntes pedagógicos, 2, 1-16. Recuperado de: https://cedoc.infd.edu.ar/upload/En_Busqueda de una Unidad de Analisis.pdf

Bernstein, B. (1989). Clàses, códigos y control. Barcelona: Akal.

Bourdieu, P. (2008). Homo Academicus. Buenos Aires: Siglo Veintiuno.

Caballero, E. R. (2008). Comprensión lectora de los textos argumentativos en los niños de poblaciones vulnerables escolarizados en quinto grado de Educación Básica Primaria. Medellín: Universidad de Antioquia.

Carreño, G., Flores, M., \& Peñuelo, C. (1998). La lectura punto de partida para un aprendizaje interdisciplinario. Tunja: Universidad Santo Tomás.

Carretero, M. (1997). Constructivismo y Educación. México, D. F.: Progreso.

Cassany, D. (2006). Tras las lineas; sobre la lectura contemporánea. Barcelona: Anagrama.

Cassany, D. (2009). Para ser letrados, voces y miradas sobre la lengua. Barcelona: Paidós.

Cassany, D., Luna, M., \& Sanz, G. (2003). Enseñar lengua. Barcelana: Grao.

Castañeda, L. S., \& Henao, J. I. (1990). Taller sobre los textos de español para primaria: ventajas y alternativas. Lingüística y Literatura, 17, 21-26.

Carr, W., Benedito, V., Bravo, J. A., \& Kemmis, S. (1988). Teoría crítica de la enseñanza: la investigación-acción en la formación del profesorado. Buenos Aires: Martínez Roca.

Castro, P. J., Van der Veer, R., Burgos-Troncoso, G., Meneses-Pizarro, L., Pumarino-Cuevas, N., \& Tello-Viorklumds, C. (2013). Teorías subjetivas en libros latinoamericanos de crianza, acerca de la educación emocional. Revista Latinoamericana de Ciencias Sociales, Niñez y Juventud, 11(2), 703-718. doi:10.11600/1692715x.11217060213

Cisterna, F. (2005). Categorización y triangulación como procesos de validación del conocimiento en investigación cualitativa. Theoria, 14(1), 61-71. Recuperado de: http:/www.redalyc.org/ pdf/299/29900107.pdf

Chaparro, M. O., \& Vargas, G. D. (2004). Comprensión lectora a través del desarrollo de estrategias lúdicas a los estudiantes del grado cuarto de primaria de la I. E. Integrada Marco Antonio Quijano Rico sede Peña negra, Sogamoso. Tunja: Universidad Pedagógica y Tecnológica de Colombia.

Denzin, N. K. (2012). Triangulation 2.0. Journal of Mixed Methods Research, 6(2), 80-88. doi: $10.1177 / 1558689812437186$

Díaz, F., \& Hernández, G. (1999). Estrategias docentes para un aprendizaje significativo: una interpretación constructivista. México, D. F.: Mc Graw-Hill.

Díaz-Barriga, F., \& Hernández-Rojas, G. (2010). Estrategias docentes para un aprendizaje significativo: una interpretacion constructivista. México, D. F.: Mc Graw-Hill.

Elliott, J. (1991). El cambio educativo desde la investigación-acción. Madrid: Morata.

Esteban, M. (2003). Investigación cualitativa en educación. Fundamentos y tradiciones. Madrid: Mc Graw and Hill Interamericana.

Fernández,A. (2003). Formación pedagógica y desarrollo profesional de los profesores de universidad: análisis de las diferentes estrategias. Revista de Educación, (331), 171-197. Recuperado de: https://dialnet.unirioja.es/servlet/articulo? codigo $=670572$ 
Ferreiro, E., \& Teberosky, A. (1979). Los sistemas de escritura en el desarrollo del niño. Mexico, D. F.: Siglo Veintiuno.

Fountas, I. C., \& Pinnell, G. S. (2001). Guiding readers and writers, grades 3-6: Teaching comprehension, genre, and content literacy. Portsmouth: Heinemann.

Frade, L. (2009). Competencias lectoras y obstáculos que se presentan . México, D. F.: Inteligencia Educativa.

Friedman, A. M. (2016). Perceptual construction: Rereading. The social construction of reality through the sociology of the senses. Cultural Sociology, 10(1), 77-92. doi:10.1177/1749975515615149.

George, J. D., Fisher, A. G., \& Verhs, P. R. (2007). Tests y pruebas fisicas. Barcelona: Paidotribo.

Gívens, T. (1998). Escamas de dragón y hojas de sauce. Bogotá, D. C.: Norma.

Gómez, A. (2001). Comprensión lectora mediante el uso de los signos de puntuación. Tunja: Universidad Pedagógica y Tecnológica de Colombia.

Green, P. (2001). Critical literacy revisited. En H. Fehring, \& P. Green (Eds.), Critical literacy: A collection of articles from the Australian Literacy Educators Association (pp. 7-63). Newwark: Internacional Reading Association.

Gutiérrez, J., \& Delgado, J. M. (1999). Métodos y técnicas cualitativas de investigación en ciencias sociales. Madrid: Síntesis.

Halliday, M. (1982). El lenguaje como semiotica social. México, D. F.: Fondo de Cultura Económica.

Henao, J., \& Londoño-Vásquez, D. A. (2017). Relación literacidad, contexto sociocultural y rendimiento académico: la experiencia de la Facultad de Ciencias Empresariales de la Institución Universitaria de Envigado. Revista Encuentros, 15(01), 29-46. doi:10.15665/re.v15i1.847

Henao, J., Londoño-Vásquez, D. A., Frías, L., \& Castañeda, L. (2011). Niveles de literacidad de los estudiantes de Psicología de la Institución Universitaria de Envigado. Zona Próxima, (15), 5477. Recuperado de:

rcientificas.uninorte.edu.co/index.php/zona/article/download/2176/2359Ladis

Hernández-Sampieri, R. (2006). Los enfoques cuantitativo y cualitativo en la investigación científíca. En R. Hernández-Sampieri, C. Fernandez, \& P. Baptista (Eds.), Metodología de la investigación. México, D. F.: Mc Graw-Hill.

Hopkins, D., Joyce, B., \& Calhoun, E. (2002). A Teacher's Guide to Classroom Research. New York: Open University Press.

Isáziga-David, C. H., Gabalán-Coello, J., \& Vásquez-Rizo, F. E. (2014). La intervención académica en la construcción de una sociedad con calidad: análisis del valor agregado en el proceso formativo colombiano. Hallazgos, 11(22), 359-384. Recuperado de: http://www.scielo.org.co/pdf/hall/ v11n22/v11n22a19.pdf

Jurgenson, J. L. A. G., \& Luis, J. (2003). Cómo hacer investigación cualitativa: fundamentos y metodología. Barcelona: Paidós.

Kettula, K., Lampinen, M., Fan, F., \& Jiang, D. (2013). Chinese university teachers' experiences of a Finnish university pedagogical workshop. Trames: A Journal of the Humanities \& Social Sciences, 17(4). Recuperado de: http://www.kirj.ee/23009/

King, P. M., \& Kitchener, K. S. (1994). Developing Reflective Judgment: Understanding and promoting intellectual growth and critical thinking in adolescents and adults. Jossey-Bass Higher and Adult Education Series and Jossey-Bass Social and Behavioral Science Series. San Francisco: JosseyBass.

Kress, G. (2003). Literacy in the new media age. Nueva York: Routledge.

Larrivee, B. (2000). Transforming teaching practice: Becoming the critically reflective teacher. Reflective practice, 1(3), 293-307. doi:10.1080/14623940020025561

Londoño-Vásquez, D. A. (2008). Error analysis in a written composition. Profile Issues in Teachers ' Professional Development, (10), 135-146. Recuperado de: https://revistas.unal.edu.co/index. php/profile/article/view/10619 
Londoño-Vásquez, D. A. (2015). Jóvenes y literacidad un análisis sosiolingüístico. Medellín: Institución Universitaria de Envigado.

Marradi, A., Archenti, N., \& Piovani, J. (2007). Metodología de las ciencias sociales. Buenos Aires: Emecé.

Mirabent-Perozo, G. (1990). Aquí, talleres pedagógicos. Revista Pedagogía Cubana, 2(6), 15-25. Recuperado de: https://biblat.unam.mx/es/revista/pedagogia-cubana

Montenegro, M. P. (2010). MóniEstrategias de enseñanza en el desarrollo de la comprensión lectora de los grados primero y segundo. Barranquilla: Corporación Universitaria de la Costa.

Ovando, M. N. (2001). Teachers' perceptions of a learner-centered teacher evaluation system. Journal of Personnel Evaluation in Education, 15(3), 213-231. Recuperado de: https://link.springer.com/ article/10.1023/A:1012704809835

Parodi, G. (Ed.) (2010). Alfabetización académica y profesional en el siglo XXI: leer y escribir desde las disciplinas. Santiago de Chile: Ariel.

Philliber, W. W., Spillman, R. E., \& King, R. (1996). Consequences of family literacy for adults and children: Some preliminary findings. Journal of Adolescent \& Adult Literacy, 39(7), 558-565. Recuperado de: http://www.jstor.org/stable/40017464

Quintero, A. (2011). Diseño de proyectos de investigación cualitativa. Revista Tendencias \& Retos, (16), 313-316. Recuperado de: HYPERLINK "https://dialnet.unirioja.es/ejemplar/384999" https://dialnet.unirioja.es/ejemplar/384999

Ramírez-López, N. M. (2014). «Narrativas de vida y memorias»: conflicto escolar en el Colegio Santa Librada. Revista Latinoamericana de Ciencias Sociales, Niñez y Juventud, 12(1), 201-210. doi:10.11600/1692715x.12111042613

Restrepo-Gómez, B. (2004). La investigación-acción educativa y la construcción de saber pedagógico. Educación y Educadores, (7), 45-55. Recuperado de: http://educacionyeducadores.unisabana. edu.co/index.php/eye/article/view/548

Richardson, V. (1990). Significant and worthwhile change in teaching practice. Educational Researcher, 19(7), 10-18. doi:10.3102/0013189X019007010

Ríos-Flórez, J. A., \& Cardona-Agudelo, V. (2016). Procesos de aprendizaje en niños de 6 a 10 años de edad con antecedente de nacimiento prematuro. Revista Latinoamericana de Ciencias Sociales, Niñez y Juventud, 14 (2), 1071-1085. doi:10.11600/1692715x.14213241115

Riquelme, A., \& Quintero, J. (2017). La literacidad, conceptualizaciones y perspectivas: hacia un estado del arte. Revista Reflexiones, 96(2), 93-105.

Rosas, S. M. (2003). El programa de lectura nivel 1. Sobre la comprensión de lectura en niños que cursan el 3er grado de primaria de nivel socioeconómico medio y bajo. Lima: Universidad Nacional Mayor de San Marcos.

Sánchez-Castaño, J. A., Castaño-Mejía, O. Y., \& Tamayo-Alzate, O. E. (2015). La argumentación metacognitiva en el aula de ciencias. Revista Latinoamericana de Ciencias Sociales, Niñez y Juventud, 13(2), 1153-1168. doi:10.11600/1692715x.13242110214

Soler, L. (2004). Significado y alcances de la renovación pedagógica y didáctica de la alfabetización: Plan Iberoamericano de Alfabetización y Educación Básica -PIA-2005-2015. Bogotá, D. C.: Organización de Estados Iberoamericanos.

Torres-Velázquez, M. (2016). Lectoescritura: eventos de literacidad en preescolar. Revista Iberoamericana para la Investigación y el Desarrollo Educativo, 6(12), 1-18. Recuperado de: http://www.redalyc.org/pdf/4981/498153966015.pdf 